\title{
Materializing Memory, Mood, and Agency: The Emotional Geographies of the Modern Kitchen
}

\begin{abstract}
Drawing upon narrative and visual ethnographic data collected from households in the UK, this article explores the material and emotional geographies of the domestic kitchen. Acknowledging that emotions are dynamically related and coconstitutive of place, rather than presenting the kitchen as a simple backdrop against which domestic life is played out, the article illustrates how decisions regarding the design and layout of the kitchen and the consumption of material artefacts are central to the negotiation and doing of relationships and accomplishment of
\end{abstract}

Meal machine, experimental laboratory, status symbol, domestic prison, or the creative and spiritual heart of the home? Over the course of the past century no other room has been the focus of such intensive aesthetic and technological innovation, or as loaded with cultural significance. Kitchen design has been both a central concern of modernism and fundamental to our concept of modern life (MoMA 2014).

THAT THE KITCHEN WAS the subject of an exhibition-Counter Space: Design and the Modern Kitchen ${ }^{1}$ - curated by the Museum of Modern Art (MoMA) in New York indicates the extent to which this domestic space has been elevated from a mere site of "sanitary labour" (Saarikangas 2006: 165) to a subject of material and cultural interest among both academic and popular audiences. The above quote, taken from the exhibition's promotional website, captures some of the complexity with which many academics have wrestled when thinking about domestic kitchens over the last forty years. It is a topic that has attracted scholars from a range of disciplinary backgrounds: from feminists who have marked the kitchen out as "a zone of feminine subjection, where women must manage a ceaseless routine of work" (Floyd 2004: 62) to those who have taken a global perspective in providing revisionist histories of women's relationship with the spaces in which domestic foodwork takes place, among whom the kitchen has been reconceptualized as a site of resistance rather than one of oppression. ${ }^{2}$ domestic life. Based on fieldwork in northern England, the article examines the affective potential of domestic space and its material culture, exploring how individuals are embodied in the fabric and layout of domestic space, and how memories may be materialized in their absence.

Keywords: kitchens, consumption, materiality, agency, ethnography, emotional geographies, UK

Meanwhile, design, cultural, and social historians have explored how - in addition to the ways in which female subjectivity has been designed into kitchen spaces (Hayden 1978; Cieraad 2002; Freeman 2004; Llewellyn 2004a)-ideologies concerning nationhood (Buckley 1996; Lloyd and Johnson 2004), social class (Attfield 1995; Cieraad 2002; Hollows 2000; Llewellyn 2004b), and both production and consumption influenced the visions of architects, designers, and urban planners during the twentieth century (Freeman 2004; Jerram 2006; Johnson 2006; Saarikangas 2006; Hollows 2008). Others have explored the ways in which the kitchen has been reconstituted from a "backstage" site of production to one of socialityin the form of the kitchen-diner or living-kitchen-accessible to and converged upon by all household members and visitors alike (Hand and Shove 2004; Munro 2013).

Some have focused on the impact that technology has had in transforming the interior landscape of the kitchen (Giard 1998: 210): for example, in helping to rationalize foodwork, in allegedly deskilling consumers (Short 2006; Meah and Watson 2011), or in creating "more work for mother" (Cowan 1983). ${ }^{3}$ Importantly, the role that kitchens have played in processes of identification-particularly among migrant communitieshas not been overlooked. ${ }^{4}$ Indeed, Dutch writer, curator, and photographer Linda Roodenburg (2011: 238) suggests that the "kitchen is a metaphor of a complex, multi-cultural reality." 
Building on the sociological work of June Freeman (2004), who interviewed a sample of seventy-five British householders with newly installed kitchens, I take a geographic and visual ethnographic approach in exploring how some of the women and men I have met during my encounters in domestic kitchens in the UK have appropriated and made use of these spaces. Presenting four case-study kitchens, I illustrate the ways in which ideas about aesthetics, design, form, and function converge in envisaging the consumption of spaces that may have originally been imagined for quite different purposes to those required by modern consumers. Often operating within structural or financial constraints, occupants of these four households illustrate the ways in which both experiential knowledge acquired over the life-course informs practices of appropriation and consumption, and how-ultimately - "the hardware of material culture figures in the doing of things" (Watson and Shove 2008: 70) and is, therefore, crucial to the effective accomplishment and performance of everyday life. While kitchen spaces and their objects are revealed to be sites in which mundane practices converge, so, too, do they emerge as having affective potential wherein they do more than provide a backdrop to social and domestic life. Indeed, the materiality of the kitchen figures as crucial in processes of identification, negotiation, and relationality by which it has moved "frontstage" in the emotional topography of domestic life where, suggests Rolland Munro (2013: 218), one's sense of being in the world is magnified rather than diminished.

Implicit in my conceptualization of the kitchen within this essay is an understanding of home as an emotional space, experienced in both embodied and psychological ways. Referring to geography's "emotional turn," Bondi et al. (2005: 1) argue that our emotions

"affect the way we sense the substance of our past, present and future.... Whether we crave emotional equilibrium, or adrenaline thrills, the emotional geographies of our lives are dynamic, transformed by our procession through childhood, adolescence and middle and old age, and by more immediately destabilising events such as birth and bereavement, or the start or end of a relationship."

In keeping with the growing scholarship concerned with "the dynamic, recursive relation between emotions and space or place" (Anderson 2009: 188-89), this article foregrounds the situatedness of the kitchen within the complex, emotional geography of domestic life. Following Hockey et al. (2005: 135), who suggest that both objects and spaces have their own agency, I focus on the material culture of the kitchen and how these carry a sedimentation of significances (Hockey et al. 2001: 755) that can narrate the untold stories of lives being lived
(Gregson et al. 2007; Llewellyn 2004b), those having been lived, as well as those that are imagined (Meah and Jackson forthcoming). This has, however, not always been the case and, in the next section, I briefly illustrate how these changes have been effected historically before turning my attention to each of my case study kitchens.

\section{Consuming the "Heart of the Home"}

That the modern kitchen has been regarded - by some - as a "laboratory" (Lloyd and Johnson 2004; Van Caudenberg and Heynen 2004) or a "machine for the preparation of meals" (Llewellyn 2004b: 234) is reflected in the emphasis placed by architects and designers on functionalism, operational efficiency, and the principles of household management, making it a site of mundane practice in which space, objects, social conventions, and human agency converge. The impact of these management discourses in influencing the ideas of design professionals in the Global North during the first half of the twentieth century has been examined by a number of scholars. ${ }^{5}$ Louise Johnson (2006), for example, reports the application of time-and-motion principles in Australia, Europe, and North America by the 1920s, leading to the identification of a "working triangle" 6 -the sink, food storage, and cooking areas. ${ }^{7}$ Rooted in the effective relationship between humans, their environments, and nonhuman agents, this is a theme that persists in contemporary design discourses regardless of shifting rationales concerning aesthetics.

However, while architectural discourses of the interwar period prescribed the kitchen as a space for food-"work", 8 its meanings to those who occupy it extend beyond this narrow conceptualization, not least since cooking is increasingly represented less as "work" and more as a recreational, leisure activity (Roos et al. 2001; Holden 2005; Short 2006; Aarseth 2009; Swenson 2009; Cairns et al. 2010), and one with increasing appeal to men (Hollows 2003; Swenson 2009; Meah 2014b; Meah and Jackson 2013). Moreover, the centrality of the kitchen within domestic life has resulted in its conceptualisation as 'the metaphor for family life' (Craik 1989: 57). Martin Hand and colleagues (2007) observe that regardless of shifts which may have taken place in the functionality of the kitchen (facilitated by a range of technologies that make for more efficient, productive, or accomplished cooking), perhaps the most significant development has been "the idea that the kitchen constitutes the symbolic heart of the home" (2007: 675, emphasis in original), a theme also echoed by Freeman (2004). That a shift has taken place in how kitchens are conceptualized in the UK over the last decade or so is reflected in a kitchen manufacturer's advertisement published in 
Good Housekeeping in 2002, in which the kitchen is described as "somewhere you want to spend time, where you feel comfortable, where you can simply live your life" (cited in Hand et al. 2007: 675)

Given that Elizabeth Shove and colleagues (2007: 22) report that British kitchens are replaced every seven years or so, this room has become constituted as an important site of consumption, renovation, and renewal. However, as proponents of current theories of practice, ${ }^{9}$ these authors contend that rather than simply being signifiers of identity, material artefacts-including those implicated in the design and layout, as well as the technologies of the kitchen-are not passive objects, but interact with people in the form of routinized practices, giving them agency in actively configuring their users (ibid.: 23). ${ }^{10}$ However, while objects and intermediaries may enable participants to achieve "better" or faster results in terms of cooking and cleaning for example, evidence from Hand et al.'s (2007) study of kitchens (and bathrooms) indicates that such items are also implicated in the performance-or doing-of "family" and, therefore, of everyday life. Indeed, many of their respondents identified the kitchen table as the key item facilitating a vision of kitchen-based sociality that resonates within idealized notions of this room being the symbolic heart of the home. ${ }^{11}$ In what follows, I explore the ways in which some of my participants' kitchens have been imagined, appropriated, and consumed, illustrating how spaces and material artefacts, combined with experiential knowledge, converge in forms of practice that reveal their agency in the effective accomplishment and performance of everyday life. In keeping with the growing scholarship concerning emotional geographies, whereby emotions are acknowledged as being dynamically related to and co-constitutive of place (Bondi et al. 2005; Davidson and Milligan 2004; James 2013), this essay foregrounds the situatedness of the kitchen within the emotional topography of domestic life.

\section{Research Context and Methods}

The data reported here emerge from a research study, based in northern England, which focused-primarily_on patterns of continuity and change in families' domestic kitchen practices within living memory. ${ }^{12}$ As part of a broad interest in domestic food provisioning practices, including routine activities of food shopping, storage, preparation, eating, and disposal, the research also explored the spatial contexts in which such practices take place. Food-focused life history interviews enabled participants to speak about their memories of kitchens from their childhood and earlier lives, as well as those currently inhabited, while ethnographic work - utilizing a digital camera and small digital video recorders - in the form of provisioning "go-alongs" (Kusenbach 2003) (including accompanied shopping trips, guided kitchen, garden and allotment tours, and meal preparation), facilitated the recording of the visual dimensions of their engagement with food and food-related spaces. I interviewed twenty-three members - aged 17-92-of eight families, with at least two generations represented in each family. Ethnographic work was completed with fifteen of the seventeen participating households. ${ }^{13}$

While narrative interviews emphasize the discursive dimensions of participants' experiences and perceptions, the ethnographic work offered the advantage of capturing how domestic "kitchen life" (Wills et al. 2015) is enacted and performed in each household, facilitating what Sarah Pink (2004: 10) has referred to as an "anthropology of the senses." This meant that I was able to directly observe and record the interplay of form and function, ergonomics and aesthetics, within the spaces in which foodwork was undertaken. These included gardens and allotments, where some participants grew their own produce, food storage in cellars, ${ }^{14}$ pantries, ${ }^{15}$ and utility areas, and spaces where food is consumed. I also acquired a feel for what it was like to be in these spaces while groceries were put away and food prepared, including the practical or physical limitations imposed by the design of the space itself, as well as the material objects utilized within it. Indeed-acknowledging the effect that my presence may have had, and that the method does not provide unmediated access to participants' daily lives - the go-along enabled me to engage with my participants' stream of experiences and practices as they moved through, and interacted with, their physical and social environments (Kusenbach 2003: 463). ${ }^{16}$

In the case study examples that follow, I draw upon both the narrative and visual data, along with my fieldnotes, in an attempt to reconstruct some of the kitchens I encountered during my fieldwork. My aim is to embody the individuals, their experiences and frustrations, as they interact in a material environment that, to some degree or another, appeared to be idealized-either now or in the past-as the symbolic heart of their homes.

In each household, participants reflected upon the process of planning and designing their current or imagined kitchens, which for some was experienced as a positive and collaborative activity, but in others was reported as a source of contestation or disagreement, wherein different desires and preferences have had to be negotiated and compromises reached, with particular material objects serving to ameliorate any dissatisfaction with the outcome. Although the kitchen was, for all, a functional space where meals were produced, such spaces are also reported as having an affective 
role for those who occupied them, either in mobilizing memories shared within them, or in facilitating a transformation in mood via interaction with the physical space and the material objects found therein. Indeed, all of these kitchens hummed with life and meaning that went beyond the preparation of food (see Bennett 2006; Meah and Jackson forthcoming).

The first case study illustrates how kitchens can be sites of hauntings, or absent presences, the material culture therein bearing witness both to their history and to the lives of those who have occupied or currently occupy them; thus being implicated in the performance of family life, a negotiated and socially learned process. The second looks at kitchens as a site of consumption, where dominant discourses concerning design and aesthetics are rejected by the occupants and material objects consumed not just for what they make possible in terms of identification or accomplishment, but for their agency in configuring mood or feeling. The third and fourth kitchens illustrate the processes by which disagreement is negotiated and resolved in how new kitchens are imagined by different household members. Specifically, the third introduces the theme of restlessness and how, when individuals are unable-either due to a lack of resources or a failure to reach a compromise - to transform the physical environment of the kitchen, other items may be consumed that mitigate a sense of discontent. In the final kitchen case study, we see what happens when discourses concerning ergonomics and aesthetics compete via its occupants' needs and desires. In this case, it is the house itself-rather than simply the needs or preferences of the owners - that succeeds in shining through and, in doing so, demonstrates the affective potential of space in contributing to domestic harmony or discord. Combined, these kitchens provide an insight into how the materiality of the kitchen figures not just as a backdrop to the activities that take place therein, but are revealing of the ways in which emotions and place are co-constitutive.

\section{Absent Presences}

This first case study epitomizes the idea that kitchens have symbolic significance as the heart of the home but, simultaneously, it also makes visible their temporal nature as sites in which past(s) and present can converge in the form of absent presences (Hetherington 2004). Anne Elland (63) and her husband, Mike, had lived in their house for almost thirty years when I interviewed her in August 2010. The couple had raised three sons here and all but the youngest had now left home. Located in an affluent part of the city where most of the fieldwork took place, the house is a large and imposing semi-detached property at the end of a long drive. It dates back to the Victorian period and retains many of its original architectural features. The kitchen is located to the rear of the house; a room large enough to easily accommodate a farmhouse table and six chairs, along with a range of fitted oak units, an oak dresser, and a number of freestanding appliances, including an expensive French range cooker.

At one end of the kitchen is a door leading to the hallway into the rest of the house, and another leading down to the cellar where, among other things, a chest freezer is stored, along with vegetables, which are neatly laid out on a stone slab, an original design feature for storing food prior to the introduction of electric refrigeration.

In one corner of the high-ceilinged kitchen is a bell system linking each of the bedrooms, the lounge, and formal dining room to the kitchen; evidence of the social status of those who might once have occupied this property-perhaps wealthy industrialists. In spite of its size, the room only has two windows, one of which is positioned over a porcelain sink overlooking a large garden. These features point toward this space having been the domain of servants relegated to the rear of the house, beyond public view, with only a narrow aspect onto the outside world.

Over the years, the Elland family have reconstituted this space as something more than a site in which the messy business of feeding the household is undertaken by servants. It is, or at least was when their sons lived at home, the "throbbing heart of the house" (Roodenburg 2011: 226), at the center of which is the kitchen table. Indeed, when interviewed, Anne's eldest son, John (41), remembered this table as not just being the place where the family would eat, but where he and his brothers would do their homework and his father would read the papers, along with the evening ritual of "always listen[ing] to the news and then The Archers which was generally around the time we'd finished our tea . . at five past seven."17

Prior to my meeting Anne, John had explained the process his parents had engaged in during the planning of the kitchen. Having an engineering background, his father was a very practical man and designed and fitted the kitchen himself; however, he did so in consultation with Anne regarding her needs of the space. John envisaged that this will be a process that he and his own wife will replicate when they eventually replace their current kitchen. Of this he said:

It'll be a joint project to decide on, in the same way that my parents' was... My Dad built that kitchen pretty much and, you know, I remember him saying to my Mum, "I can get you a bit of marble and put it in the worktops so you can roll your, erm, pastry out," "yeah that's a good idea" and "where'd, where do you want this and where do you want that?" you know, and it kind of, it was er . . . it was a dialogue 
about how they wanted it to look and where they wanted things and where, you know, how it, where things would be most useful and functional.

When I spent the afternoon with Anne in her kitchen, she confirmed this, adding that her husband had built the units and worktops ergonomically so that they would be at elbow height for her, making this a more comfortable space for her to prepare food in. While these accounts of how the space was planned and installed perhaps point toward the design of gender into space (see Llewellyn 2004a), they have additional significance if we consider them as evidence of how relationships and domestic life are negotiated and reproduced within this family. Indeed, the kitchen becomes a space through which John learns about processes of negotiation and consideration of others' needs and requirements in the doing of relationships and aspires to a similar approach within his own marriage.

These narratives highlight the way in which Anne was literally designed into and embodied within the space, her aesthetic tastes also reflected in the red floral wallpaper and appliances chosen to accessorize with the color of the cooker. But there is more than this; the displayed collections of china and crockery that were given as gifts at the time of the couple's marriage testify to a life shared by Anne and Mike which spanned over six decades. How, then, is this kitchen experienced by Mike following Anne's unexpected death less than three years after I encountered the telling of this kitchen's story? Rewatching the video footage and hearing Anne's voice and her laughter at a time when I was starting to think about the kitchen in terms of what Pierre Nora (1989) has referred to as lieux de memoire (sites of memory), I was struck by how this kitchen - both with evidence of its distant history and functioning remaining, and with one of its former users designed into it-illustrates the ways in which material objects enable reminiscence, materialize memory, and facilitate the maintenance of embodied and emotional connections with events or people from the past (Meah and Jackson forthcoming) (see Figure 1).

Two years after his mother's death, I asked John whether Anne's absent presence (Hetherington 2004) has been experienced as a comfort, or as a haunting (Miller 2001) by him and his father as they perhaps stand at the sink and overlook a view once shared by Anne. Here, John indicates that while his mother's absence is felt through her choice of décor and the photographs of her that are displayed in other parts of the house, it is perhaps experienced most keenly via the kitchen since the back door is used as the main entrance to the house: as soon as the family walk through the door they are reminded that Anne is no longer there. He suggests that

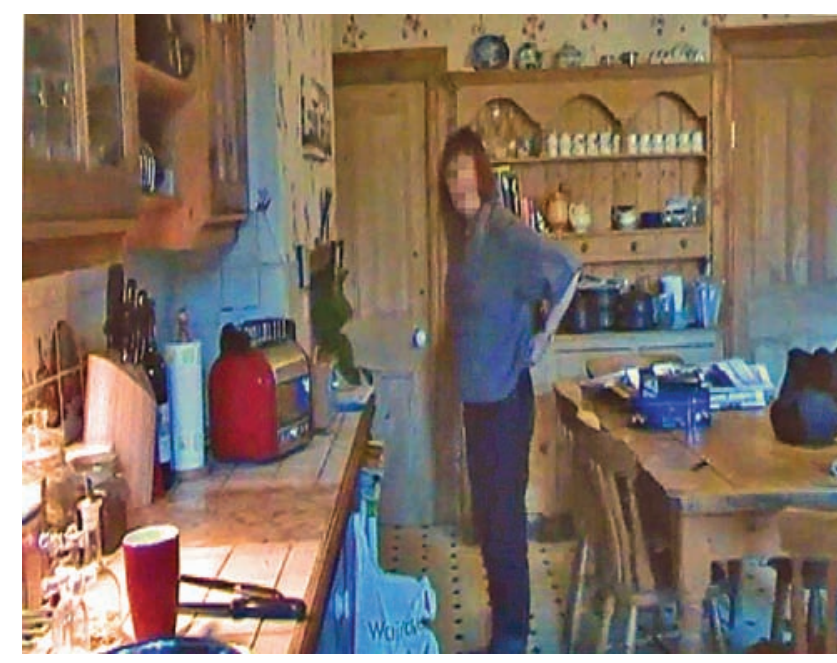

FIGURE 1: Video still of Anne Elland in her kitchen, December 13, 2010. PHOTOGRAPH BY ANGELA MEAH (C) 2010

rather than being a comfort-for now at least-his mother's absent presence is experienced as a haunting:

It's still a strange experience going round to see my Dad and my Mum never being there. There is so much of her in the house ... Unlike some couples, my parents always made joint decisions on decorating, pictures, furniture et cetera so the whole house is very much a reflection of both my parents which only heightens my Mum's absence all over the house. The same applies to the kitchen really. Although my Mum was the main cook of the family the kitchen always felt-like the cliché says-the heart of the home and not necessarily my Mum's domain. It still feels the same, to me anyway, although it's a lot more untidy these days! I don't think I've got to the point where the house is a comfort; every time I walk through the back door I feel her absence.

Through this kitchen we are reminded of Yi-Fu Tuan's (1977: 144) suggestion that "home is an intimate place. We think of the house as home and place, but enchanted images of the past are evoked not so much by the entire building, which can only be seen, as by its components and furnishings, which can be touched and smelled as well." Seen from this perspective, objects are ascribed more than mere practical or aesthetic value; they are reframed as companions to our emotional lives (Turkle 2011: 5).

\section{Configuring Identities and Feeling}

In this next kitchen, we see the multiple ways in which consumption figures into the doing of everyday life: in what-and how - things are consumed (or rejected), and how the effects extend beyond practices of identification and accomplishment. Liz Butler (55) lives with her husband, Philip, and their two daughters, aged 16 and 17. At the time of our interview, Liz and Philip had occupied their home for twenty-five years. 


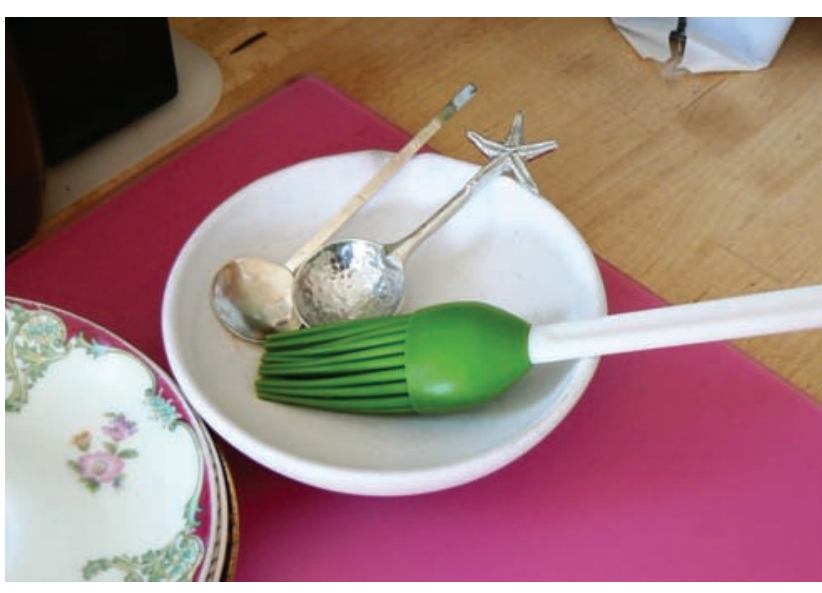

FIGURE 2: The mood-transforming spoon and other kitchen utensils. PHOTOGRAPH BY ANGELA MEAH (C) 2010

The house is a semi-detached property-probably dating to the immediate post-Second World War period-located in a built-up, suburban area on the outskirts of an industrial city. Positioned on a hill, the rear-facing kitchen overlooks a long, sloping garden, well-stocked with trees, a view that can be seen while standing at the kitchen sink.

The kitchen had been redesigned three years prior to the household's participation in the study, Liz explaining that they had had the space extended, meaning that it effectively doubled in size. The daughter of a coal miner, Liz recalled, with fondness, the kitchen she grew up in as a place where "everything" happened - from cooking and eating, bathing in front of the fire, listening to music and dancing. In contrast with this, and in spite of it having been extended, there was no room for a table in her current kitchen; instead, the separate dining room was accessed through a doorway below a stainless steel shelf laden with pans. Nonetheless, there was a sense that the kitchen was something of a nerve center and hive of activity within the house; or at least it was Liz's nerve center.

Although Liz had once aspired to a career in catering, as a working mother she had to satisfy her culinary passions by becoming an enthusiastic grower and producer of food, using her kitchen to store produce from her garden and allotment, as well as transforming fruit that she had grown into preserves and cordials, and her vegetables into wholesome meals for her family. Here, she escaped the stresses of her job, describing baking as a form of relaxation. Since her husband and daughters did not share her enthusiasm for cooking, the kitchen was a space largely occupied by Liz.

While some other participants had replaced existing kitchens with fairly standardized fitted units guided by design professionals or sales advisors, Liz reported having resisted the advice of "experts," including her original joiner, who had told her that the vision she had for her new kitchen was not achievable in the existing space. Far from being a passive consumer-either of the current fashion for continuous work surfaces and unified cupboard arrangements (Freeman 2004: $3^{8)}$ with integrated appliances that create the illusion of order, or of "expert" advice that did not fit her requirementsduring her interview, Liz reported that she "told them what I wanted and kind of worked with them" to achieve it.

Liz reported that her basic requirements were that "I don't want fitted [units], I don't like fitted . . . I want a reclaimed wooden floor," and that there should be lots of natural light. The outcome of these stipulations was that the off-shot exten$\operatorname{sion}^{18}$ was constructed in brick up to sink height but, above this, the walls and back door were constructed of glass and unplasticized polyvinyl chloride (UPVC). In contrast with the kitchen in the Ellands' older property, this is an incredibly light space, where one can look out over the garden and part of the city below while washing up, facilitating a sense of connection with the outside world.

All the appliances are freestanding and, instead of base units, there are freestanding cupboards, under which there is space for storage baskets (where, among other things, Liz stores her preserves), while canned goods are kept on shelves in a storage space under the staircase off the main hallway. In her interview, Liz asserted:

I really don't like cupboards . . I think they're a waste of time. Why would you want cupboards [laughs]; they stop halfway up the wall, they collect dirt and dust and everything on top of there.

In Figure 2-a collage of separate images, pasted together to form a panorama representing half of Liz's kitchen - we can see the design solution that resolved her aversion to cupboards. This is a worktop-to-ceiling, open unit, the upper shelves of which are accessible using the wooden stool positioned in front of the fridge-freezer. ${ }^{19}$ While the open-plan nature of the space may, on the one hand, appear to be untidy and is inconsistent with the clinical, well-concealed conditions imagined by many Modernist designers who envisaged the kitchen as a site of production, at the same time it is revealing of the lives being led herein, including, for example, Liz's commitment to sustainable consumption, manifested in the pile of recycling and egg-trays for reuse on the far right of the image.

While Liz may not fit the image of the passive "housewifeconsumer" (Hollows 2000: 125) ${ }^{20}$ who might be "led" into consuming ideas about design and layout that may be en vogue, she nonetheless admits to a fondness of kitchen gadgetry. 


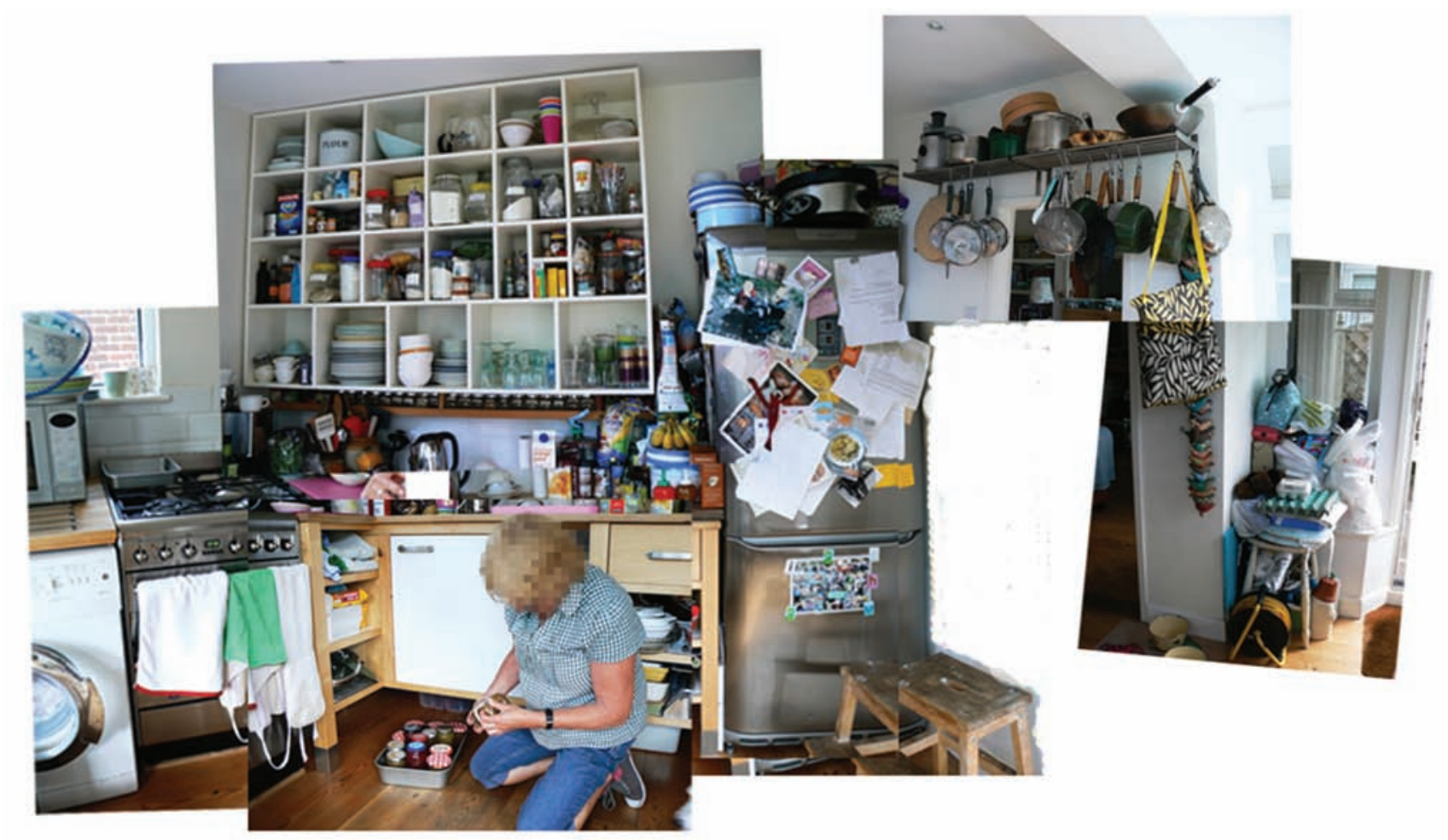

FIgURE 3: Liz Butler in her nonstandard kitchen, August 17, 2010. PHOTOGRAPH BY ANGELA MEAH (C) 2010

Commenting on the filmed cooking observation, in my fieldnotes I observed:

Using a silicone brush, Liz smears the pan with olive oil and I comment on her gadgets. She says that her husband laughs at her, "but I use them all," she says, and she shows me a silver teaspoon (see Figure 3): "gorgeous, I bought that just to cheer myself up. I should cry more often!" A spoon that helps transform someone's mood. .

Here, we are reminded of Shove et al.'s (2007: 23) observation regarding how "material artefacts, rather than being passive objects, actively "configure their users," not just in terms of identity, skill, and accomplishment, but also in terms of feeling or mood.

Liz's account of the making of her kitchen and the significance of particular objects within it illuminate the ways in which - for some - this space, at the heart of the home, has meaning that is grounded in comfort, belonging, and identity. ${ }^{21}$ If, as Bachelard (1994 [1958]) suggests, our house is our corner of the world, then Liz's kitchen is her special corner of this world, experienced as a revitalizing space within the emotional geography of her everyday existence. Here, she is sequestered from both the stresses of work and the demands of her family, where she can look out on her garden and the world beyond from her kitchen window, indulge her passion for cooking, and daydream in peace (ibid.: 4-6).

The kitchens described above are-or were- used primarily by women. In my next two kitchens, reflecting shifts in domestic kitchen use over the last two decades, the principal users are men. In each case there is evidence of contestation over the design of the kitchen, reinforcing the suggestion that kitchens are becoming increasingly "crowded" spaces (Meah and Jackson 2013).

\section{A Restless Kitchen}

In this third kitchen, we explore the restlessness (Shove et al. 2007) that emerges when the occupants are unable to reach agreement concerning its physical layout. While there is contestation over one user's aspiration to transform this space into a place-the hub of the house-the consumption of technologies helps mitigate reported frustrations; such technologies having agency both in facilitating the accomplishment of foodwork tasks and in enabling at least one of the occupants to feel better about these tasks.

Sally (40) and Stuart (42) live with their children, Ben (5) and Rachel (7), and their cat and dog in a small terraced 
cottage located in a village in the Derbyshire countryside. The property is modest and simply furnished, the couple having undertaken renovation work in keeping with its original character. The couple are very thrifty and, despite modest incomes, Stuart reported-with some pride-that all the work undertaken on the property has been completed without incurring any debt. However, the household finances have yet to stretch to the renovation of the kitchen, which is a source of frustration for Stuart, an enthusiastic everyday cook, baker, and maker of preserves. The kitchen was among the smallest that I visited; perhaps twelve feet long and four wide"galley" shaped-with little room for more than one person at a time, which made for a challenging experience while filming during a hot Saturday afternoon in June 2010.

The kitchen comprises a freestanding wooden storage unit, on which I observed Stuart kneading and proofing bread dough (see Figure 4), and a selection of white, wallmounted cupboards and matching base units in between the sink and the freestanding cooker. A door is missing on one of the wall units and a row of tiles is missing to one side of the cooker. A stainless steel sink and separate hot and cold taps highlight the age of this kitchen. Because storage space is at a premium, the tops of the cupboards are used to store cereals and cookware, and the microwave is located on top of the fridge-freezer at one end of the kitchen. Most of the household's food is stored in an outbuilding, accessed via steps down to a paved yard. In addition to the washing machine and dryer, here we find an upright freezer, where bulkbought meat, batch-cooked meals, cakes, bread, and other bulky items are kept, along with a shelving unit containing a selection of homemade preserves, canned goods, and other nonperishable items. As with the previous two case studies, Stuart and Sally's foodwork space does not comply with the Modernist vision of eliminating extraneous movements if all food storage spaces are taken into consideration.

Figure 4 gives some idea as to the spatial constraints experienced by users of this kitchen, of which Stuart observed: "It does my head in. I need a bigger kitchen; well, I don't need one, I would like one." The kitchen literally feels crowded when occupied by a cook, small children and/or a mediumsized dog; even more so when a camera-wielding researcher is thrown in.

Stuart reported that he is currently "doing battle" with Sally over what to do with the kitchen. His vision is to remove the wall that separates the kitchen and the dining room, seen on the left of Figure 4. He said:

I'd love to have a big kitchen, if it was me that wall would come straight out and, you know, I'd like to have a big kitchen where, it's like

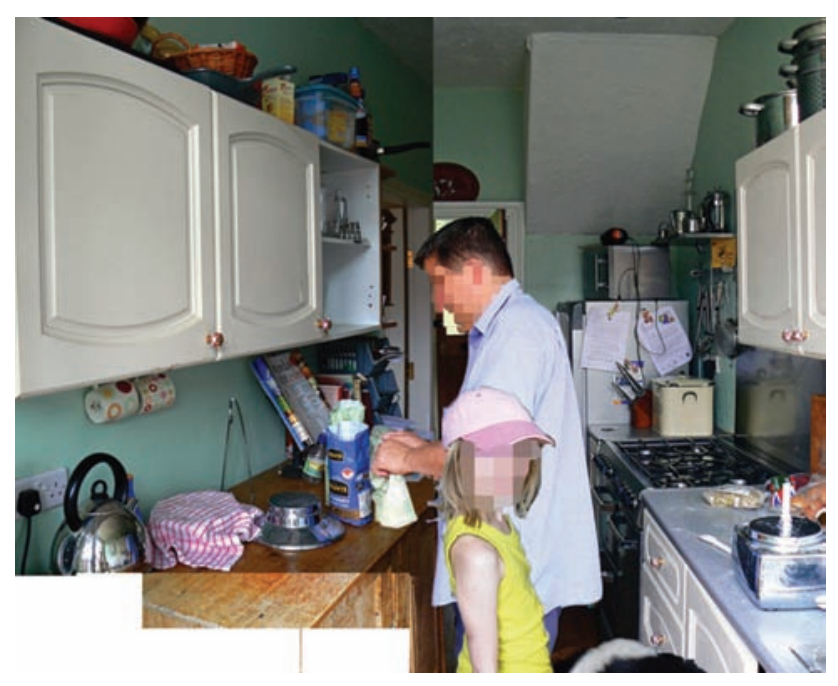

FIgure 4: Stuart Charles, Rachel, and the family dog in their "crowded kitchen," June 26, 2010.

PHOTOGRAPH BY ANGELA MEAH (C) 2010

you said, the hub of the house, so you can sit round there but... when we have guests round to eat I'm generally chatting through the wall if you know what I mean, shouting through. . . . I just want a whole big kitchen. I want it all out, you've got this lovely fireplace [in the dining room], you can make a, 'cause the kitchen's, that's the only thing we've not spent on.

What Stuart longs for is the type of "democratized" kitchen-dining space (Munro 2013) envisaged by some Modernist designers, such as Jane Drew, who aimed to reduce women's isolation backstage in pre-war kitchens (see Llewellyn 2004a). In these visions, the kitchen moved frontstage, the cook and their activities on public display (Munro 2013). While some (for example, Cieraad 2002) have suggested that the current popularity of open-plan kitchens among men, in particular, is attributable to their enthusiasm for "performing," Stuart seemingly longs for a space that will simultaneously have meaning as the hub of the house, as well as one where he can interact with other people without having to shout through walls. However, the reason that he is unable to realize this is because - regardless of whether occupied by a male or female user-Sally prefers to have the "kitchen mess" separate from the rest of the house. The kitchen therefore emerges not as a site in which contestation takes place, but one over which different needs and preferences of its users compete.

Stuart's experiences echo those of Shove et al.'s (2007: 26) participants who reported what the authors describe as "restless kitchens," based upon the relations of "having" and "doing" being out of synch; a sense of having to "make do." For Stuart, making-do is partly facilitated by two not inexpensive 
technological intermediaries that enable him to achieve a sense of both enjoyment and accomplishment in cooking, while at the same time not feeling enslaved in a cramped and isolated space. The first was the stainless-steel range cooker, described as "my baby. It's my little toy"; the second was a Magimix food processor, of which he says: "I couldn't be without it." I speculated as to what his grandmother would have done to have had a machine like this and Stuart responded:

That thing saves me so much time in the kitchen. You wouldn't believe what I make with it. I think I pretty much use it for everything I cook that I can think of, even if it's just down to slicing, grating, whizzing, mixing.

The food mixer, along with its various attachments, has agency in both speeding up some tasks and making others less laborious, enabling Stuart to complete more food-related tasks, and also freeing up more leisure time. It may be argued that these kinds of labor-saving technologies have transformed domestic cooks into "unskilled spectators" or mere pushers of buttons (Giard 1998: 212) that simultaneously serve to further "enslave" (Wajcman 1995) and bind women to domesticity (Murcott 1983: 33). However, the shifting gendered landscape of the domestic kitchen (which has seen the "democratization" [Meah and Jackson 2013] of many foodwork activities) means that women are no longer assumed to be sole consumers of such technologies.

Clearly, this kitchen is a source of contestation in this household: the existing space being a source of frustration to Stuart, the imagined kitchen beyond the realms of possibility for his wife. While Stuart aspires to a more "democratic" kitchen-dining space, it is perhaps the case that Sally is aware of the limits of "democracy," particularly if-as in some of the other households that took part in the study-there remains a persistence of gendered constructs regarding the nature of cleanliness and order and what is considered to be "acceptable." However, rather than causing an unbridgeable gap in the emotional topography of the household, the couple negotiate ways of managing the mismatch between their needs and preferences, with specific objects-such as the food mixer and the cooker-ameliorating Stuart's experience of the kitchen while simultaneously satisfying Sally's need to contain the messy business of foodwork.

\section{Aligning Ergonomics and Aesthetics}

In this final kitchen, there is also evidence of disagreement between the occupants. In this case, however, the tension emerges when discourses concerning ergonomics and aesthetics are out of synch. Laura Anderson (63) and her husband, Ted (65), have been married for over forty years and have lived in their current home since 2003. On buying what is - now-an impressive Edwardian villa, the couple set about an extensive program of renovation involving architects in redesigning the layout of the original kitchen, dining, and utility areas. In her interview, Laura suggested that she had wanted an opportunity to de-clutter their domestic space after years of accumulating "stuff." She said:

I didn't want it to be starkly modern, I wanted, somehow, the look to reflect the period. I'd got into this idea that you've got to let the house shine through and so, minimalist, but not in any kind of . . But, so, in terms of the kitchen I'd got, you know, it was more the look of it that was important to me . . . it was little, tiny. But in terms of the design and function, you know, the relationship between that bit of it was very much [Ted's] doing.

During his interview, Ted reiterated that the kitchen has to "look right" and "be a nice space to be in," but he added: "the way in which a kitchen works, the space has to be laid out appropriately."

When the couple moved into the property, the kitchen had been hidden away at the rear of the house, a space now utilized as a utility room and downstairs cloakroom. They effectively moved the kitchen into the original dining room, constructing a U-shaped space that became the food preparation area. A Belfast sink ${ }^{22}$ and drainer is located in the "curve" of the $\mathrm{U}$, a space above this having been cut into the wall overlooking the dining room (see Figure 5). Rather than acting as a simple serving hatch, the large opening with wine glasses overhanging and stools positioned on the other side gives this more of a sense of being a social space through which cook and visitors - who naturally gravitate toward the rear of the housecan remain connected. Although not a kitchen-diner-as imagined by Munro (2013) - the Andersons' kitchen nonetheless invites visitors "to view the 'production' of the hospitality they anticipate enjoying" (ibid.: 217), whether this is a cup of tea or a multi-course meal. ${ }^{23}$

On the other side of the kitchen, at one "end" of the $\mathrm{U}$, is a large "American" fridge-freezer, which Ted described as "my treat." This was an appliance ascribed with "intelligence," since - like Liz Butler's fridge-freezer-it is self-cleaning and automatically adjusts its temperature depending on how full it is. At the other end of the $\mathrm{U}$, set within the chimney breast, is a Lacanche cooker. ${ }^{24}$ Ted emphasized the "robust" nature of this semi-professional appliance, and-unlike Stuart Charlesdescribes it as "not like a toy, it's a proper bit of kit . . . it just makes me feel really good about using it." As with Liz's silver teaspoon, the cooker has agency in enabling Ted to feel good 


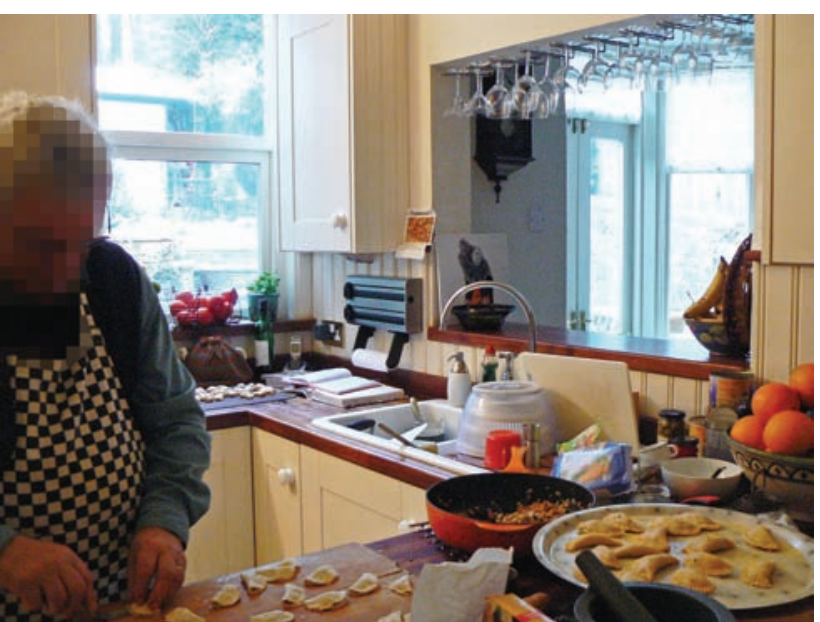

FIgURE 5: Ted Anderson preparing food ahead of a Christmas party, December 23, 2010.

PHOTOGRAPH BY ANGELA MEAH (C) 2010

about what he's doing, in his case-perhaps-facilitating a greater sense of accomplishment.

Additionally, the house is given agency in-literally-being enabled to "shine through" via the reinstatement of the previously bricked-over chimney breast in order to accommodate the powerful extractor required to service the cooker. Of this, Ted reported:

When we opened it, it was, it looked promising and . . . so we had er, this, this built up and the arch reinstated, the arch had been taken out fifty years ago or something, so the arch was put back in, and then this big industrial, erm, extractor which was built for the space.

Ted went on to explain:

I arranged the racks around [the cooker] so everything's within. . . you wouldn't have a kitchen without being able to reach everything really handily ... and then the other space around it was arranged so that, the, the dishwasher can easily. . . feed into the cupboards with all the stuff and the bin, that the waste is right next to the, underneath the worktop and so on, so it's (better) to work in a very basic ergonomic way.

I observed both Ted and Laura in the kitchen on several occasions over a period of months, the last being ahead of a Christmas party in 2010, when I was greeted by a kitchen warmed by an oven baking Spanish pastry dishes, the aroma of which filled the air, and the sound of a classical radio channel playing Christmas carols; a cozy and inviting haven on a cold, dark winter's day (see Figures 5 and 6).

I watched Ted as he cleared the space on the food preparation area, wiping spilled polenta into the pull-out bin with a cloth. Having forgotten what he had told me-almost a year earlier-about this aspect of the layout, I asked if this

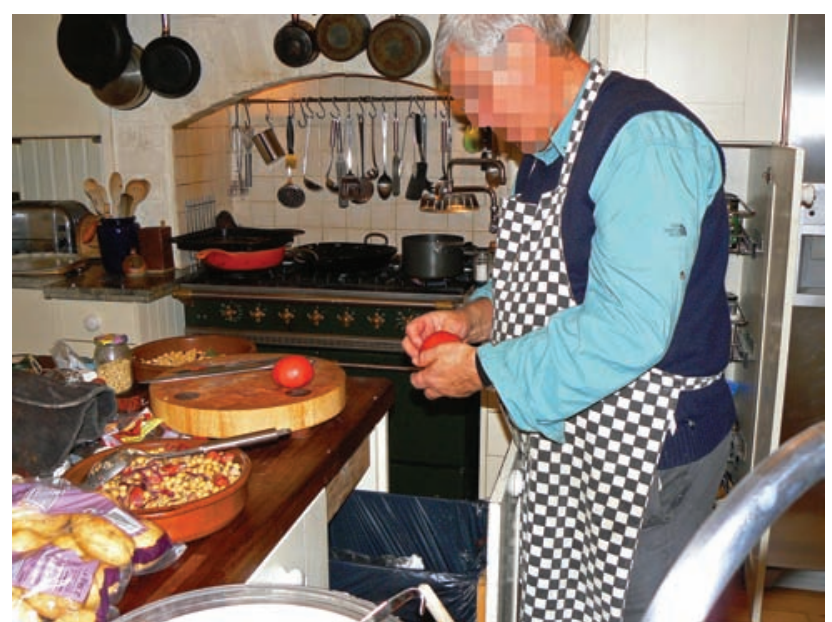

FIGURE 6: Ted Anderson's "serious cooker" and ergonomically designed bin.

PHOTOGRAPH BY ANGELA MEAH (C) 2010

function was built into the design: the idea that you could sweep food debris directly into the bin. He responded: "It was completely deliberate." Laura, however, reported that she had not picked up on this feature until one of their sons' friends had made her aware of the possibility of wiping things straight into the bin; she had never considered this herself. Here, this older couple unsettle conventional gendered stereotypes regarding the relative importance of form and function because it is Ted who is the principal user of this kitchen, not his wife.

However, Ted's determination to have a space "that worked well for cooking rather than just looking nice" ignored a parallel resolve on Laura's part that functionality should not override aesthetics in certain key areas. For example, the kitchen had been fitted with wooden worktops that, over time, had started to blacken around the sink. Laura told me that Ted's proposed solution was to replace the worktops with black granite ones. Her response: "that's absolutely not, so not the look I want," and she reported the exchange between them:

. . he kept saying to me, "you won't talk to me about this, you won't plan this ... and I still don't know what you want," and I said, "well, basically, I don't want what you want, do I? You know what I do like, you know what I don't like so." And he's like, "oh, come on then," and we had a bit of a, you know, I said, "we'll talk about this. .."

As with some of the previous case studies, the kitchen is revealed to be a site through which relational differences are contested and negotiated. While Mike Elland works with his wife to create a space that works for her, and Stuart Charles has to concede to Sally's stubbornness about the division of their domestic space, between the oldest of our couples we see 
a process of dialogue leading to the achievement of a solution that was agreeable to both Ted and Laura. While there has been speculation about the relative power that men and women wield in the democratized order of contemporary kitchen life, it is clear that in each of these households, women have the final say, regardless of whether they are the principal users of the space. ${ }^{25}$ In the case of the Anderson household, Laura ascribes the kitchen with an agency of its own that-she believes-should serve her wider project of enabling the house to "shine through." That she succeeds in this is reflected in Ted conceding that although his preference would have been to knock through to the dining room to create a kitchen-diner, "that wouldn't have suited the house."

\section{Conclusion: Kitchens and the Emotional Geographies of the Home}

The case studies reported here illustrate the point that rather than being simple "meal machines" or "domestic prisons," kitchens are a central site within the emotional topography of domestic life. Indeed, their significance is not restricted to either functionality or aesthetics; they are also a key site in the emotional geography of the home. Narrative and observational data collected from these households indicate that creating a space in which "you want to live your life" is far from a straightforward process. In addition to managing structural and financial constraints, individuals may find themselves going against the advice of so-called experts, and for couples at different points across the life-course, this is further complicated by the requirement to accommodate the needs and preferences of other members of the household. The kitchens that have been given life within this essay have not just been sites of contestation, compromise, and concessions, but have proved an important feature in the emotional development of both their owners and subsequent generations. By way of discussions about the design of a kitchen, John Elland learned about how couples communicate effectively in relationships, an ideal learned from his parents to which he aspires in his own marriage. Likewise, Stuart and Sally's children may have learned about how compromise can be achieved through negotiation. Importantly, they may have also learned that kitchens are not spaces occupied exclusively by women, and that cooking is something that can be a source of satisfaction and pleasure.

Additionally, while particular objects are crucial to the dynamics and performance of everyday life (Shove et al. 2012), for example in enabling individuals to achieve faster or more accomplished results, importantly we see the affective potential of domestic space and its material culture. A spoon, for example, can be mood enhancing in the same way that the open-plan layout of a space might facilitate a sense of connectedness with other people, or a connection with the world beyond while remaining safe in one's own corner of it. Likewise, a kitchen table can both facilitate, and become a metaphor for, family life, while simultaneously materializing memories among those who may have sat at it.

Whether conjuring up imagined former occupants, children who have grown up and left home, or a late spouse, we see how personal histories become embodied in the structural fabric of each kitchen, transforming them from spaces in which food is prepared or consumed into places where lives are remembered and retold. Indeed, kitchens emerge as a key site in which memory is materialized (Meah and Jackson forthcoming), particularly in relation to deceased loved ones, whose presence may haunt via objects or practices, thus foregrounding material culture as the centerpiece of emotional life (Turkle 2011: 6). Seen in this light, kitchens are brought frontstage within the emotional topography of domestic life, within which converge "memory and nostalgia for the past, everyday life in the present and future dreams and fears" (Blunt and Varley 2004: 3). @

\section{Acknowledgments}

I would like to thank Peter Jackson, Lissa Caldwell, and the anonymous reviewers for their extremely useful comments and suggestions on an earlier draft of this paper. I would also like to express enormous gratitude to my participants who gave so generously of their time, sharing their memories and opening up their kitchens to me. In particular, I would like to thank John Elland for his additional reflections following his mother's death after the completion of the study.

NOTES

1. The exhibition was on display from September 15, 2010-May 2, 2011.

2. For a review of this literature, see Meah $2014 \mathrm{a}$.

3. On cooking technologies, see, for example, Silva 2000; Truninger 2011. On cold storage, see Isenstadt 1998; Shove and Southerton 2000; Watkins 2006. On the parallel histories of the freezer and microwave oven, see Cockburn and Ormrod 2000.

4. See, for example, Pascali 2006; Supski 2006; Longhurst et al. 2009. There is also evidence of appropriation of kitchens by occupants of public housing in the UK (Miller 1988) and Soviet Russia (Reid 2002).

5. Freeman (2004: 25-54) provides a good general account. Others have commented on housing projects undertaken during the interwar period: Jerram (2006) provides a critique specific to Germany, Saarikangas (2006) on Finland, and Llewellyn (2004a, 2004b) on Britain. Hand and Shove (2004) also illustrate how changing kitchen "regimes" can be documented in popular lifestyle magazines. 
6. Johnson illustrates six variations (according to kitchen shape) on the working triangle.

7. The application of time-and-motion methods in the analysis of kitchen practices has been satirized in the Nordic film Kitchen Stories (Salmer fra Kjøkkenet, 2003).

8. Elsewhere (Meah 2016) I consider how the kitchen can be understood as a barometer of ideological dialectics during the interwar and post-World War periods.

9. See also Reckwitz 2002; Schatzki 2002; Warde 2005; Shove and Pantzar 2010; Shove et al. 2012.

10. Similar observations are also made by David Sutton (2014), writing from within the anthropological tradition. Reporting his ethnographic work on cooking and skill among the people of Kalymnos, Sutton highlights the significance of individuals' use of particular tools which may or may not facilitate skilled practice. Indeed, he notes that his participants' reflections point toward a "distributed agency between humans and objects" (2014: 74) where neither one nor the other is responsible for a successful outcome, but a combination of both.

11. Marianne Gullestad (1984) has reported that Norway is a "kitchen table society" premised upon strong female networks. This is something that has also been echoed in the literature concerning migrant and minority populations in the Global North (see note 21). 12. This study was part of an international program of research, Consumer Culture in an "Age of Anxiety" (CONANX), funded by an Advanced Investigator Grant awarded to Peter Jackson by the European Research Council (2009-12).

13. The fieldwork took place over an eighteen-month period between February 2010 and August 2011.

14. Basement areas in older types of houses.

15. Walk-in storage areas, not necessarily directly linked to the kitchen.

16. Interviews were digitally recorded and transcribed verbatim, each participant being assigned a pseudonym. Contemporaneous reflexive fieldnotes were written in tandem with analysis of the audio and visual material, still images being taken from the video footage to capture moments of practice that were not photographed directly. 17. The Archers is a popular, long-running radio drama set in the English countryside.

18. This refers to an extension from the property, usually in terraced houses, where a former outdoor toilet or coal-shed has been converted into a kitchen.

19. A combined refrigerator and freezer, usually with the refrigerator above the freezer.

20. See also Attfield 1995; Partington 1995; Lloyd and Johnson 2004.

21. On the experiences of migrant and minority populations, see

Barolini 2005; Supski 2006; Longhurst et al. 2009.

22. A deep rectangular kitchen sink, traditionally made of glazed white porcelain

23. A kitchen-diner is a kitchen with a dining area within it

24. Lacanche is a brand of range-cookers originating in Burgundy, France.

25. See Chapman 1999; Meah 2014a; Meah and Jackson 2013.

\section{REFERENCES}

Aarseth, Helene. 2009. "From Modernized Masculinity to Degendered Lifestyle Projects: Changes in Men's Narratives on Domestic Participation 1990-2005." Men and Masculinities 11: 424-40.

Anderson, Ben. 2009. "Emotional Geography." In The Dictionary of Human Geography, fifth edition, ed. D. Gregory, R. Johnston, G. Pratt, M. Watts, and S. Whatmore, 188-89. Chichester: Wiley-Blackwell.
Attfield, Judy. 1995. "Inside Pram Town: A Case Study of Harlow House Interiors, 1951-61." In A View from the Interior: Women and Design, ed. J. Attfield and P. Kirkham, 215-38. London: Women's Press.

Bachelard, Gaston. 1994 [1958]. The Poetics of Space. Boston: Beacon Press.

Bennett, Katie. 2006. "Kitchen Drama: Performances, Patriarchy and Power Dynamics in a Dorset Farmhouse Kitchen." Gender, Place and Culture 13: 153-60.

Barolini, Helen. 1997. "Appetite Lost, Appetite Found." In Through the Kitchen Window: women explore the intimate meanings of food and cooking, ed. A. Avakian, 2228-234. Oxford: Berg.

Blunt, Alison, and Ann Varley. 2004. "Geographies of Home." cultural geographies 11: 3-6.

Bondi, Liz, Joyce Davidson, and Mick Smith. 2005. "Introduction." In Emotional Geographies, ed. J. Davidson, L. Bondi, and M. Smith, 1-16. Aldershot: Ashgate.

Buckley, Sandra. 1996. "A Guided Tour of the Kitchen: Seven Japanese Domestic Tales." Environment and Planning D: Society and Space 14: 441-61.

Cairns, Kate, Josée Johnston, and Shyon Baumann. 2010. "Caring about Food: Doing Gender in the Foodie Kitchen." Gender and Society 24(5): 591-615.

Chapman, Tony. 1999. "You've got him well trained': The Negotiation of Roles in the Domestic Sphere." In Ideal Homes? Social Change and Domestic Life, ed. T. Chapman and J. Hockey, 163-80. London: Routledge.

Cieraad, Irene. 2002. "'Out of my kitchen!' Architecture, Gender and Domestic Efficiency." Journal of Architecture 7: 263-79.

Cockburn, Cynthia, and Judith Ormrod. 2000. Gender and Technology in the Making. London: Sage.

Cowan, Ruth Schwartz. 1983. More Work for Mother: The Ironies of Household Technology from the Open Hearth to the Microwave. New York: Basic Books.

Craik, Jennifer. 1989. "The Making of Mother: The Role of the Kitchen in the Home." In Home and Family: Creating the Domestic Sphere, ed. G. Allan and G. Crow, 48-65. London: Macmillan.

Davidson, Joyce, and Christine Milligan. 2004. "Embodying Emotion, Sensing Space: Introducing Emotional Geographies." Social and Cultural Geography 5(4): 523-32.

Floyd, Janet. 2004. "Coming Out of the Kitchen: Texts, Contexts and Debates." cultural geographies 11: 61-73.

Freeman, June. 2004. The Making of the Modern Kitchen. Oxford: Berg.

Giard, Luce. 1998. "Doing Cooking." In The Practice of Everyday Life, Volume 2: Living and Cooking, ed. M. De Certeau, L. Giard, and P. Mayoll, 149-247. Minneapolis: University of Minnesota Press.

Gregson, Nicky, Alan Metcalfe, and Louise Crewe. 2007. "Identity, Mobility, and the Throwaway Society." Environment and Planning D: Society and Space 25: 682-700.

Gullestad, Marianne. 1984. Kitchen-Table Society. Oslo: Universitetsforlaget.

Hand, Martin, and Elizabeth Shove. 2004. "Orchestrating Concepts: Kitchen Dynamics and Regime Change." Good Housekeeping and Ideal Home: Home Cultures 1(3): 235-56.

_ and Dale Southerton. 2007. "Home Extensions in the United Kingdom: Space, Time, and Practice." Environment and Planning D: Society and Space 25: 668-81.

Hayden, Delores. 1978. "Two Utopian Feminists and Their Campaigns for Kitchenless Houses." Signs 4(2): 274-90.

Hetherington, Kevin. 2004. "Secondhandedness: Consumption, Disposal, and Absent Presence." Environment and Planning D: Society and Space 22: 157-73. 
Hockey, Jenny, Bridget Penhale, and David Sibley. 2001.

"Landscapes of Loss: Spaces of Memory, Times of

Bereavement." Ageing and Society 21: 739-57.

- 2005. "Environments of Memory: Home Space, Later Life

and Grief." In Emotional Geographies, ed. J. Davidson,

L. Bondi, and M. Smith, 135-46. Aldershot: Ashgate.

Holden, T. J. M. 2005. "The Overcooked and the Underdone: Masculinities in Japanese Food Programming." Food and Foodways 13(1-2): 39-65.

Hollows, Joanne. 2000. Feminism and Femininity and Popular Culture. Manchester: Manchester University Press. - 2003. "Oliver's Twist: Leisure, Labour and Domestic Masculinity in The Naked Chef." International Journal of Cultural Studies 6: 229-48.

- 2008. Domestic Cultures. Maidenhead, UK: Open University Press.

Isenstadt, Sandy. 1998. "Visions of Plenty: Refrigerators in America around 1950." Journal of Design History 11(4): 311-421.

James, Allison. 2013. "Home Talk: Girls Talking about Family Togetherness." Home Cultures 10(3): 315-28.

Jerram, Leif. 2006. "Kitchen Sink Dramas: Women, Modernity and Space in Weimar Germany." cultural geographies 13: 538-56.

Johnson, Louise. 2006. "Browsing the Modern Kitchen: A Feast of Gender, Place and Culture (Part 1)." Gender, Place and Culture 13(2): $123-32$.

Kusenbach, Margarethe. 2003. "Street Phenomenology: The GoAlong as Ethnographic Research Tool." Ethnography 4(3): 455-85.

Llewellyn, Mark. 2004a. "Designed by Women and Designing Women: Gender, Planning and the Geographies of the Kitchen in Britain 1917-1946." cultural geographies 10: 42-62. . 2004b. 'Urban Village' or 'White House': Envisioned Spaces, Experienced Places, and Everyday Life at Kensal House, London in the 1930s." Environment and Planning D: Society and Space 22: 229-49.

Lloyd, Justine, and Louise Johnson. 2004. "Dream Stuff: The Postwar Home and the Australian Housewife, 1940-1960." Environmental and Planning D: Society and Space 22: 251-72.

Longhurst, Robyn, Lynda Johnston, and Elsie Ho. 2009. "A Visceral Approach: Cooking 'at Home' with Migrant Women in New Zealand." Transactions of the Institute of British Geographers 34: $333-45$.

Meah, Angela. 2014a. "Reconceptualizing Power and Gendered Subjectivities in Domestic Cooking Spaces." Progress in Human Geography 38: 671-90.

_ _ 20104b. "Reconceptualising 'Masculinity' through Men's Contributions to Domestic Foodwork." In Masculinities and Place, ed. P. Hopkins and A. Gorman-Murray, 191-208. Farnham: Ashgate.

— 2016. "Extending the Contested Spaces of the Modern Kitchen." Geography Compass 10(2): 41-55.

, and Peter Jackson. 2013. "Crowded Kitchens: The

'Democratisation' of Domesticity?” Gender, Place and Culture 20: $578-96$.

- , and Peter Jackson. Forthcoming. "Re-imagining the Kitchen as a Site of Memory." Social and Cultural Geography. www. tandfonline.com/dx.doi.org/10.1080/14649365.2015.1089587.

__ , and Matt Watson. 2011. "Saints and Slackers: Challenging

Discourses about the Decline of Domestic Cooking. Sociological Research Online 16(2). www.socresonline.org.uk/16/2/6.html.

Miller, Daniel. 1988. "Appropriating the State in the Council Estate." Man 23(2): 353-72.

. 2001. "Possessions." In Home Possessions, ed. D. Miller, 107-21. Oxford: Berg.

Munro, Rolland. 2013. "The Disposal of Place: Facing Modernity in the Kitchen-diner." In Waste Matters: New Perspectives on Food and Society, ed. D. Evans, H. Campbell, and A. Murcott, 212-31. Oxford: Wiley-Blackwell.

Murcott, Anne. 1983. "Women's Place: Cookbooks' Images of Technique and Technology in the British Kitchen." Women's Studies International Forum 6(1): 33-39.

Museum of Modern Art (MoMA). 2014. www.moma.org/ interactives/exhibitions/2010/counter_space (accessed 12 August 2014).

Nora, Pierre. 1989. "Between Memory and History: Les Lieux de Mémoire." Special issue, "Memory and Counter-Memory." Representations 26: 7-24.

Partington, Angela. 1995. "The Designer Housewife in the 1950s." In A View from the Interior: Women and Design, ed. J. Attfield and P. Kirkham, 206-14. London: Women's Press.

Pascali, Lara. 2006. "Two Stoves, Two Refrigerators, Due Cucine: The Italian Immigrant Home with Two Kitchens." Gender, Place and Culture 13(6): 685-95.

Pink, Sarah. 2004. Home Truths: Gender, Domestic Objects and Everyday Life. Oxford: Berg.

Reckwitz, Andreas. 2002. "Toward a Theory of Social Practices: A Development in Culturalist Theorizing." European Journal of Social Theory 5: 243-63

Reid, Susie. E. 2002 "Cold War in the Kitchen: Gender and the De-Stalinization of Consumer Taste in the Soviet Union under Khruschev." Slavic Review 61: 211-52.

Roodenburg, Linda. 2011. "Essay." In Kitchen Portraits, ed. E. Klein Wolterink, 226-38. Amsterdam: Galerie Bart.

Roos, Gun, Ritva Prättälä, and Katrina Koski. 20o1. "Men, Masculinity and Food: Interviews with Finnish Carpenters and Engineers." Appetite 37: 47-56.

Saarikangas, Kirsi. 2006. "Displays of the Everyday: Relations between Gender and the Visibility of Domestic Work in the Modern Finnish Kitchen from the 1930s to the 1950s." Gender, Place and Culture 13(2): 161-72.

Schatzki, Theodore. 2002. The Site of the Social: A Philosophical Account of the Constitution of Social Life and Change. Philadelphia: Pennsylvania University Press,

Short, Frances. 2006. Kitchen Secrets: The Meaning of Cooking in Everyday Life. Oxford: Berg.

Shove, Elizabeth, and Dale Southerton. 2000. "Defrosting the Freezer: From Novelty to Convenience-A Narrative of Normalisation." Journal of Material Culture 5: 301-19.

Shove, Elizabeth, Matt Watson, Martin Hand, and Jack Ingram. 2007. The Design of Everyday Life. Oxford: Berg.

Shove, Elizabeth, and Mika Pantzar. 2010. "Understanding Innovation in Practice: A Discussion of the Production and Reproduction of Nordic Walking." Technology Analysis and Strategic Management 22(4): 447-61.

Shove, Elizabeth, Mika Pantzar, and Matt Watson. 2012. The Dynamics of Social Practice. London: Sage.

Silva, Elizabeth. 2000. "The Cook, the Cooker and the Gendering of the Kitchen." Sociological Review 48(4): 612-28.

Supski, Sian. 2006. "It was another skin': The Kitchen as Home for Australian Post-war Immigrant Women." Gender, Place and Culture 13(2): 133-41.

Sutton, David. 2014. Secrets from the Greek Kitchen: Cooking, Skill, and Everyday life on an Aegean Island. Oakland University of California Press.

Swenson, Rebecca. 2009. "Domestic Divo: Televised Treatments of Masculinity, Femininity and Food." Critical Studies in Media Communication 26(1): 36-53.

Truninger, Monica. 2011. "Cooking with Bimby in a Moment of Recruitment: Exploring Conventions and Practice Perspectives." Journal of Consumer Culture 11(1): 37-59. 
Tuan, Yi-Fu. 1977. Space and Place: The Perspective of Experience. Minneapolis: University of Minnesota Press.

Turkle, Sherry. 2011. "Introduction: The Things That Matter." In Evocative Objects: Things We Think With, ed. S. Turkle, 3-10. Cambridge, MA: MIT Press.

van Caudenberg, Anke, and Hilde Heynen. 2004. The Rational Kitchen in the Interwar Period in Belgium: Discourses and Realities. Home Cultures, 1(1), 23-50.

Wajcman, Judy. 1995. "Domestic Technology: Labour-saving or Enslaving?" In The Politics of Domestic Consumption: Critical Readings, ed. S. Jackson and S. Moores, 217-23. London: Prentice Hall/Harvester Wheatsheaf.
Warde, Alan. 2005. "Consumption and Theories of Practice." Joumal of Consumer Culture 5: 131-53.

Watkins, Helen. 2006. "Beauty Queen, Bulletin Board and Browser: Rescripting the Refrigerator." Gender, Place and Culture 13(2): $143-52$.

Watson, Matt, and Elizabeth Shove. 2008. "Product, Competence, Project and Practice: DIY and the Dynamics of Craft Consumption." Journal of Consumer Culture 8: 69-89.

Wills, Wendy J., Angela Meah, Angela M. Dickinson, and Frances Short. 2015. "I don't think I ever had food poisoning': A Practicebased Approach to Understanding Foodborne Disease That Originates in the Home." Appetite 85: 118-25. 